
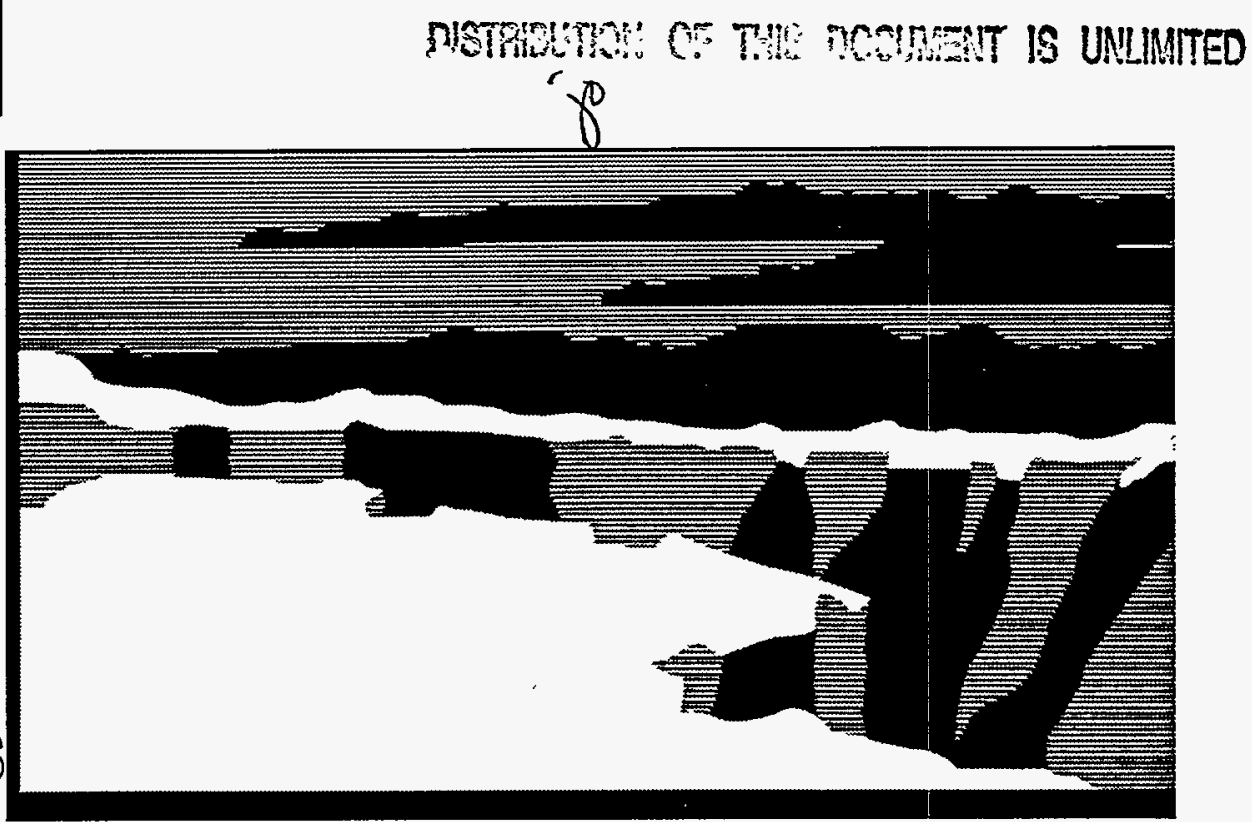

Los Alamos National Laboratory, an affirmative action/equal opportunity employer, is operated by the University of California for the U.S. Department of Energy under contract W-7405-ENG-36. By acceptance of this article, the publisher recognizes that the U.S. Government retains a nonexclusive, royalty-free license to publish or reproduce the published form of this contribution, or to allow others to do so, for U.S. Govemment purposes. The Los Alamos National Laboratory requests that the publisher identify this article as work performed under the auspices of the U.S. Department of Energy. 


\section{DISCLAIMERR}

Portions of this document may be illegible in electronic image prodnets. Images:areproduced from the best arailable original document. 
Preprint LA-UR-96-32/2

CONF-970404-1

Title: ULTRA-HIGH TRITIUM DECONTAMINATION OF SIMULATED FUSION FUEL EXHAUST USING A 2-STAGE PALLADIUM MEMBRANE REACTOR

Author(s): Stephen a. Birdsell

R. Scott Willms

Richard C. Wilhelm
ESA-TSE

ESA-TSE

ESA-TSE

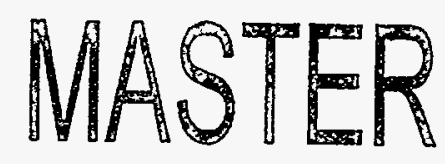

Submitted To: FOURTH INTERNATIONAL SYMPOSIUM ON FUSION NUCLEAR TECHNOLOGY

APRIL 6-11, 1997 - MEIKI KINENKAN, TOKYO JAPAN

\section{DISCLAIMER}

This report was prepared as an account of work sponsored by an agency of the United States Government. Neither the United States Government nor any agency thereof, nor any of their employees, makes any warranty, express or implied, or assumes any legal liability or responsibility for the accuracy, completeness, or usefulness of any information, apparatus, product, or process disclosed, or represents that its use would not infringe privately owned rights. Reference herein to any specific commercial product, process, or service by trade name, trademark, manufacturer, or otherwise does not necessarily constitute or imply its endorsement, recommendation, or favoring by the United States Government or any agency thereof. The views and opinions of authors expressed herein do not necessarily state or reflect those of the United States Government or any agency thereof. 


\title{
ULTRA-HIGH TRITIUM DECONTAMINATION OF SIMULATED FUSION FUEL EXHAUST USING A 2-STAGE PALLADIUM MEMBRANE REACTOR
}

\author{
Stephen A. Birdsell, R. Scott Willms and Richard C. Wilhelm \\ Mail Stop C-348 \\ Los Alamos National Laboratory \\ Los Alamos, NM 87545 \\ 505-667-2138
}

\section{ABSTRACT}

A 2-stage cold (non-tritium) PMR system was tested with the ITER mix ${ }^{*}$ in 61 days of continuous operation. No decrease in performance was observed over the duration of the test. Decontamination factor (DF) was found to increase with decreasing inlet rate. Decontamination factors in excess of $1.4 \times 10^{5}$ were obtained, but the exact value of the highest DF could not be determined because of analysis limitations.

Results of the 61-day test were used to design a 2stage PMR system for use in tritium testing. The PMR system was scaled up by a factor of 6 and built into a glovebox in the Tritium Systems Test Assembly (TSTA) of the Los Alamos National Laboratory. This system is approximately $1 / 5^{\text {th }}$ of the expected full ITER scale. The ITER mix was injected into the PMR system for 31 hours, during which $4.5 \mathrm{~g}$ of tritium were processed. The $1^{\text {st }}$ stage had $\mathrm{DF}=200$ and the $2^{\text {nd }}$ stage had $\mathrm{DF}=2.9 \times 10^{6}$. The overall $\mathrm{DF}=5.8 \times 10^{8}$, which is greater than ITER requirements.

\section{INTRODUCTION}

A Palladium Membrane Reactor (PMR) system is under consideration for the tritium plant for the International Thermonuclear Experimental Reactor (ITER). The ITER reactor exhaust will contain tritiated impurities such as water and methane. Tritium will need to be recovered from these impurities for environmental and economic reasons. For this purpose a promising device called a palladium membrane reactor (PMR) has been proposed. The PMR is a combined permeator and catalytic reactor. Shift catalysts are used to foster reactions such as water-gas shift, $\mathrm{H}_{2} \mathrm{O}+\mathrm{CO} \rightarrow \mathrm{H}_{2}+\mathrm{CO}_{2}$, and methane steam reforming, $\mathrm{CH}_{4}+\mathrm{H}_{2} \mathrm{O} \rightarrow 3 \mathrm{H}_{2}+\mathrm{CO}$. Due to thermodynamic limitations these reactions only proceed to partial completion. Thus, a $\mathrm{Pd} / \mathrm{Ag}$ membrane, which is exclusively permeable to hydrogen isotopes, is incorporated into the reactor. By maintaining a vacuum on the permeate side of the membrane, product hydrogen isotopes are removed, enabling the reactions to proceed toward completion.

Results of a single stage palladium membrane reactor have been reported in previous papers. Willms et al. ${ }^{1}$ processed simulated fusion fuels with a PMR, but these early experiments contained no tritium. Willms et al. ${ }^{2}$ and Birdsell and Willms ${ }^{3}$ report on tritium experiments with a single-stage PMR. Both sets of experiments were conducted at ITER relevant conditions and found to have a decontamination factor (DF=inlet tritium/outlet tritium) in the $150-400$ range.

The earlier experiments used $\mathrm{Ni} / \gamma-\mathrm{Al}_{2} \mathrm{O}_{3}$ catalyst which was not stable in the PMR environment. Pellets tended to break up into fine particles, especially when coking occurred. The need for a better catalyst and to avoid coking was apparent.

\section{CATALYST EVALUATION AND COKE PREVENTION}

Figure 1 shows a schematic drawing of a $1^{\text {st }}$ stage PMR. The PMR in the cold testbench has a Pd/Ag tube which is $61.0 \mathrm{~cm}$ long, $0.635 \mathrm{~cm}$ in diameter, and has a wall thickness of $0.0178 \mathrm{~cm}$. The stainless steel shell is $66.0 \mathrm{~cm}$ long, $2.54 \mathrm{~cm}$ in diameter, and has a wall thickness of $0.165 \mathrm{~cm}$. The annular space around the $\mathrm{Pd} / \mathrm{Ag}$ tube was filled with a catalyst and the performance was tested with an inlet mixture of $40 \mathrm{sccm} \mathrm{CH}_{4}, 50 \mathrm{sccm}$ $\mathrm{H}_{2} \mathrm{O}$, and $44 \mathrm{sccm} \mathrm{Ar}$, which is a simulated fusion fuel exhaust referred to as the "ITER Mix". Reactor temperature and pressure were $510^{\circ} \mathrm{C}$ and 590 torr, while the permeate pressure was 0.2 torr. Three types of catalyst were tested: $\mathrm{Ni} / \gamma-\mathrm{Al}_{2} \mathrm{O}_{3}$ catalyst (United Catalyst C150-8-01), $\mathrm{Ni} / \alpha-\mathrm{Al}_{2} \mathrm{O}_{3}$ (United Catalyst C11-9-09 EW), $\mathrm{Pt} / \alpha-\mathrm{Al}_{2} \mathrm{O}_{3}$ catalyst (Engelhard A-16825).

\footnotetext{
simulated ITER exhaust
} 


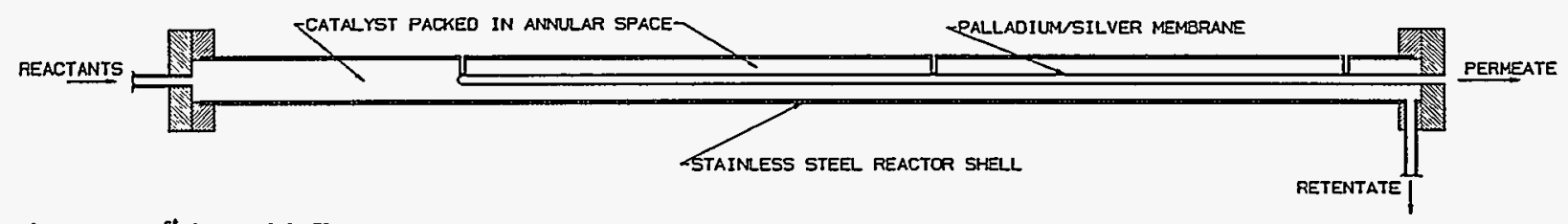

Figure 1. $1^{\text {st }}$ Stage PMR.

Both Ni catalysts exhibited significant pellet degradation after several days of operation. The catalyst was removed and areas of pellet degradation correlated with areas predicted by a numerical model to have coke deposition. ${ }^{3}$ Pellet degradation was accompanied by increasing $\mathrm{DF}$ and increasing pressure drop across the catalyst bed. These observations are consistent with the catalyst being converted from relatively large pellets to small particles. Increasing catalyst surface area results in larger reaction rates and decreasing bed porosity results in larger pressure drops. Pellet degradation occurs due to coke formation in the pores of the catalyst.

In contrast to the Ni catalyst, the Pt catalyst showed no sign of pellet degradation. After several days of operation the DF began to slowly decline, which is apparently due to coke deposition. This coke appears to be forming on the catalyst surface and blocking the active sites rather than forming in pores and causing structural damage as in the Ni catalysts.

The $\mathrm{Pt}$ bed was decoked with dilute $\mathrm{O}_{2}$ and the coking/decoking cycle was repeated. No loss of performance was observed after the cycling.

Next, to demonstrate that coking can be avoided altogether, $6 \% \mathrm{O}_{2}$ was added to the inlet mixture. This experiment was run continuously for 5 days with no decrease in performance. This result demonstrates that coke formation can be avoided regardless of the inlet $\mathrm{CH}_{4}: \mathrm{H}_{2} \mathrm{O}$ by addition of $\mathrm{O}_{2}$. At the end of these experiments the $\mathrm{Pt}$ catalyst had been used for 16 days. The catalyst was removed and inspected. No visual difference was observed between the used catalyst and a fresh sample. The catalyst was reloaded into the PMR

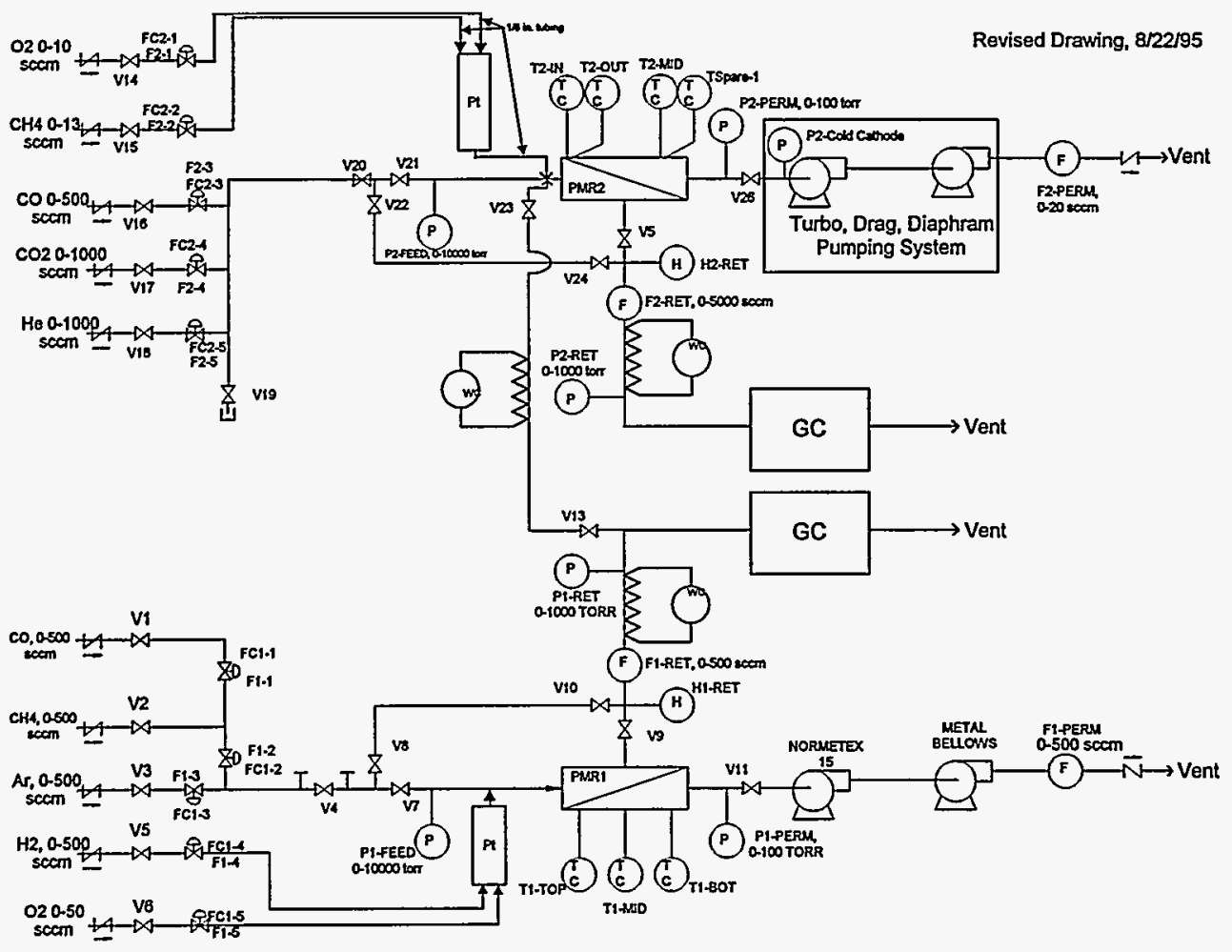

Figure 2. The 2-stage PMR cold test bench. 
and has subsequently been used in over 130 days of operation with no decrease in performance.

\section{2-STAGE COLD TESTS}

Figure 2 is a drawing of the 2-stage non-tritium PMR testbench. The testbench was designed to do either 2stage testing or simultaneous independent testing of both the $1^{\text {st }}$ and $2^{\text {nd }}$ stages. A simulated torus exhaust is produced with the mass flow controllers. Water in the simulated exhaust is produced by flowing $\mathrm{H}_{2}$ and $\mathrm{O}_{2}$ over a Pt catalyst before injection into the PMR. The combination of the Normatex 15 scroll pump and the Metal Bellows 601 pump is capable of maintaining about a 0.5 torr vacuum at the flow conditions of interest in the $1^{\text {st }}$ stage. In the $2^{\text {nd }}$ stage, the Varian V250 pumping system is capable of about a $5 \times 10^{-6}$ torr vacuum. The MTI model M200 gas chromatographs have a $\mathrm{CH}_{4}$ sensitivity of $5 \mathrm{ppm}$ and a $\mathrm{H}_{2}$ sensitivity of $0.3 \mathrm{ppm}$. The Endress and Hauser model 2850 humidity probes are calibrated from $-80^{\circ} \mathrm{C}$ to $20^{\circ} \mathrm{C}$.

The $1^{\text {st }}$ stage is the same PMR that was used in the catalyst evaluation experiments (figure 1). The shell was packed with $297 \mathrm{~g} \mathrm{Pt} / \alpha-\mathrm{Al}_{2} \mathrm{O}_{3}$ catalyst (Engelhard A$16825)$. The $2^{\text {nd }}$ stage PMR is a similar design to the $1^{\text {st }}$ stage.

The 2-stage system was tested with the ITER mix. $6.3 \% \mathrm{O}_{2}$ was added to the ITER mix to prevent coking. The temperatures of the $1^{\text {st }}$ and $2^{\text {nd }}$ stages were held at 530 and $500^{\circ} \mathrm{C}$, respectively. The $2^{\text {nd }}$ stage retentate was vented to the atmosphere, which is approximately 590 torr. The pressure drop through the $1^{\text {st }}$ and $2^{\text {nd }}$ stages was small. At the highest inlet rates, the inlet pressure was 610 torr.

The overall DF as a function of inlet rate is shown in Figure 3. The DF approaches an asymptote at $1.4 \times 10^{5}$. This asymptote represents the maximum sensitivity of our gas chromatograph and humidity probe at the outlet of the $2^{\text {nd }}$ stage. Although it was not possible to measure the maximum DF, it is known to occurs when the hydrogen in the reaction side of the PMR is in equilibrium with the hydrogen in the permeate side (i.e. at low flow).

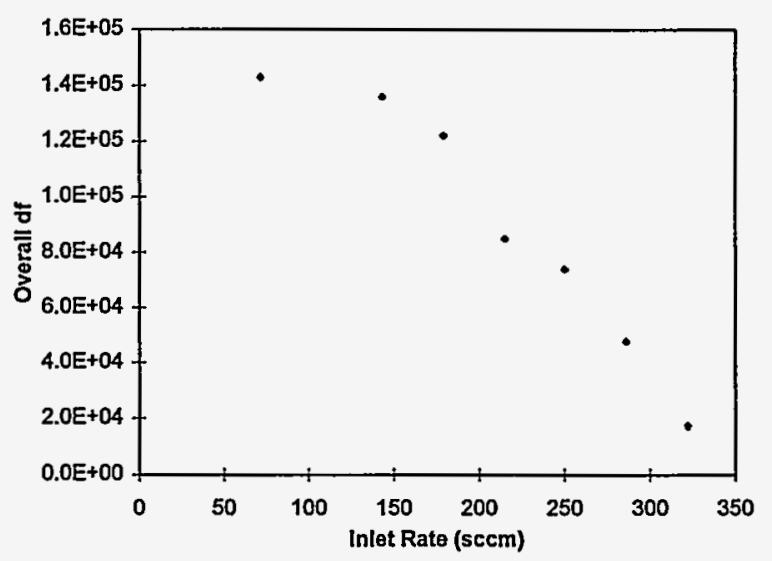

Figure 3. Overall DF for the 2-stage cold tests. Feed composition was $28 \% \mathrm{CH}_{4}, 35 \% \mathrm{H}_{2} \mathrm{O}, 31 \% \mathrm{Ar}$, and $6.3 \%$ $\mathrm{O}_{2}$.

Differentiating the relative contributions of each stage, Figure 4 shows the DF for the $1^{\text {st }}$ and $2^{\text {nd }}$ stages at various $1^{\text {st }}$ stage feed rates. Stage 1 makes its greatest contribution to the overall $\mathrm{DF}$ at low stage 1 feed rates. Its DF decreases as more "load" (i.e., flow) is placed on stagel. Though not apparent on this figure, at even lower feed rates the stage $1 \mathrm{DF}$ would reach a plateau as it became limited by the permeate pressure.

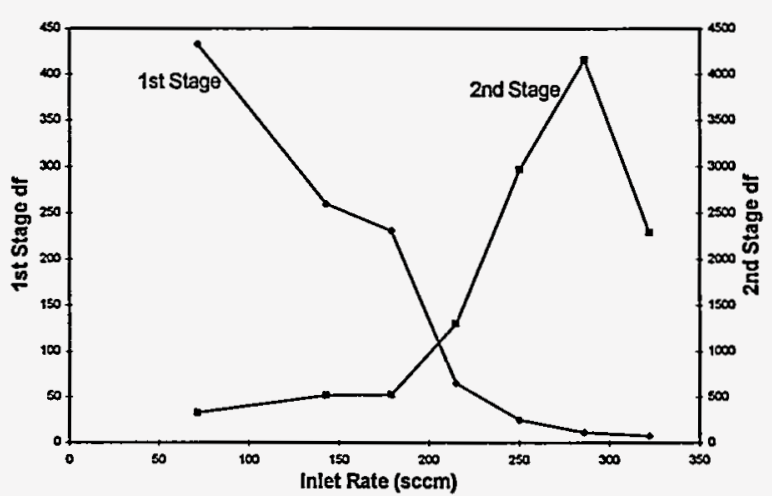

Figure 4. $1^{\text {st }}$ and $2^{\text {nd }}$ stage decontamination factors for the cold tests. Feed composition was $28 \% \mathrm{CH}_{4}, 35 \% \mathrm{H}_{2} \mathrm{O}$, $31 \% \mathrm{Ar}$, and $6 \% \mathrm{O}_{2}$.

The stage 2 behavior is more complicated since both the flow rate and composition of its feed is varying. At low stage 1 feed rates the stage $2 \mathrm{DF}$ is low since stage 1 is not leaving much hydrogen for stage 2 to process. As rates increase, more hydrogen reaches stage 2 and it exhibits an increasing DF. At the highest rate, however, stage 2 begins to show signs of rate limitation as its DF starts dropping. 


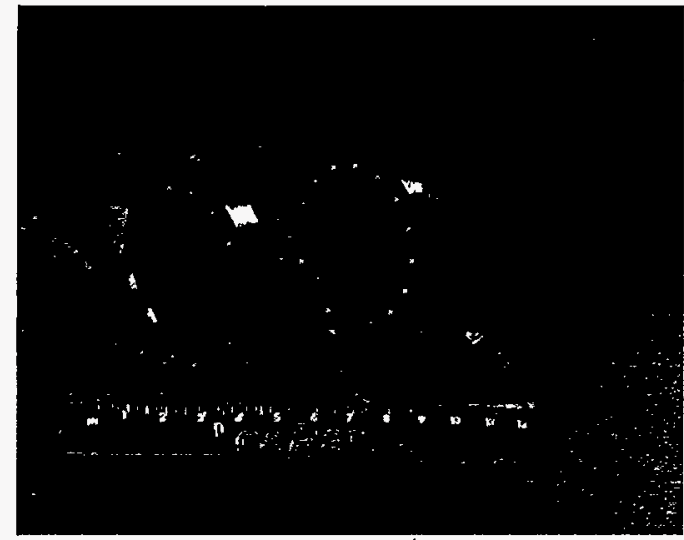

Figure 6. Photograph of the $1^{\text {st }}$ stage (background) and $2^{\text {nd }}$ stage PMRs. Catalyst is not yet loaded around the $1^{\text {st }}$ stage $\mathrm{Pd} / \mathrm{Ag}$ tubes.

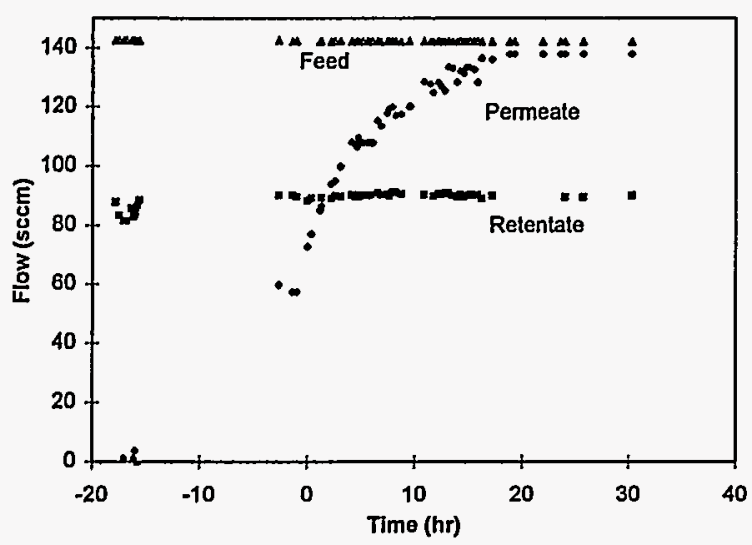

Figure 7. Feed and effluent rates for the $31 \mathrm{hr}$ tritium test of the 2-stage PMR system.

Figure 8 shows the $\mathrm{GC}$ analysis for $\mathrm{CO}$ and $\mathrm{CO}_{2}$ in the $1^{\text {st }}$ stage retentate. $\mathrm{Ar}$ is not measured with the GC, but is calculated from continuity. Figure 9 shows GC analysis for $C_{4}$ and $Q_{2}$ in the $1^{\text {st }}$ stage retentate. The remaining tritium-containing specie in the $1^{\text {st }}$ stage retentate is $\mathrm{Q}_{2} \mathrm{O}$, which was constant throughout the experiment at a much lower $\mathbf{0 . 0 0 3 5 \%}$. Decontamination factors were determined from the $\mathrm{GC}$ results and also from the ion chamber results for the $1^{\text {st }}$ stage (figure 10). The ion chamber data shows that tritium began breaking through the $1^{\text {st }}$ stage shortly after tritium injection began. The DF was 300 at the end of the experiment, but it was still slowly coming down. The DF calculated from GC data is almost constant at 200 because the GC does not distinguish between hydrogen isotopes. The GC data is considered to be more accurate because the ion chamber was calibrated over a range of 6 orders of magnitude. However, it appears that the 2 methods for measuring DF would agree quite well if the experiment had been run longer.

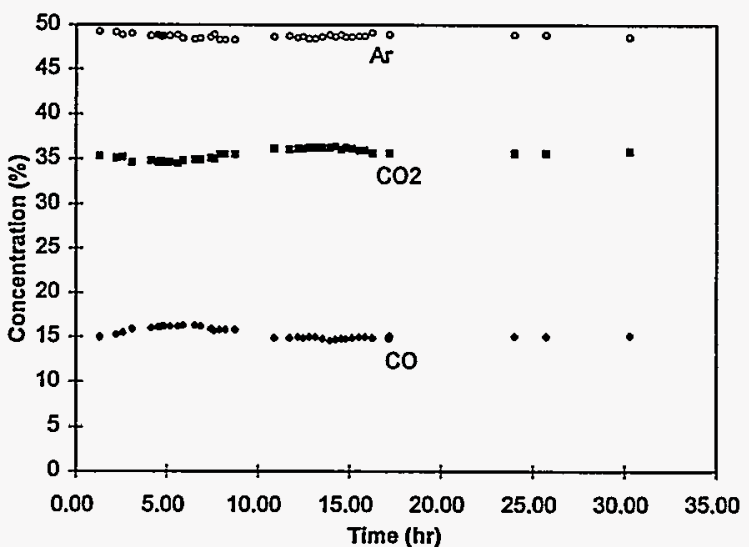

Figure 8. $\mathrm{Ar}, \mathrm{CO}$, and $\mathrm{CO}_{2}$ concentrations in the retentate of the $1^{\text {st }}$ stage.

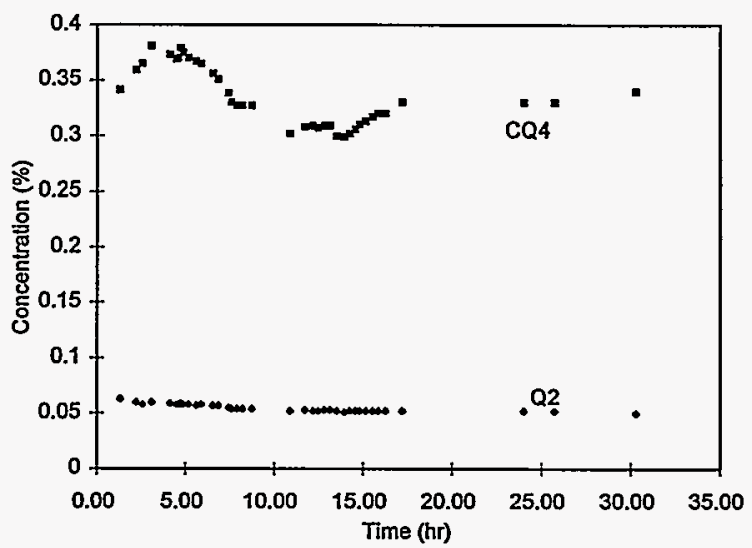

Figure 9. $\mathrm{CQ}_{4}$ and $\mathrm{Q}_{2}$ concentrations in the retentate of the $1^{\text {st }}$ stage.

Determination of the DF for the $2^{\text {nd }}$ stage retentate stream proved to be much more difficult than the $1^{\text {st }}$ stage. As in the cold tests, measurement of $\mathrm{CQ}_{4}$ and $\mathrm{Q}_{2}$ by $\mathrm{GC}$ and $\mathrm{Q}_{2} \mathrm{O}$ by humidity probe were not possible because the values were below the range of the instruments. This also proved to be the case for the ion chamber at the outlet of the $2^{\text {nd }}$ stage. Activity never rose above background for this instrument. Therefore, a bubbler method was used to measure the activity of the outlet stream. All retentate flow was oxidized over a $\mathrm{CuO}$ bed and bubbled through $200 \mathrm{ml}$ of glycol. A $1.0 \mathrm{~cm}^{3}$ sample was counted on a scintillation counter about every hour beginning with the $23^{\text {rd }}$ hour of the experiment. Accumulation of tritium was constant at approximately $2.5 \mu \mathrm{Ci} / \mathrm{hr}$ from the $23^{\text {rd }}$ hour through the end of the experiment. This outlet tritium rate divided into the $1^{\text {st }}$ stage inlet rate of $1440 \mathrm{Ci} / \mathrm{hr}$ gives an overall DF of $5.8 \times 10^{8}$. The $2^{\text {nd }}$ stage DF is $1.9 \times 10^{6}$ if it is assumed that the $1^{\text {st }}$ stage $\mathrm{DF}=200$ (i.e., $\mathrm{GC}$ method). 


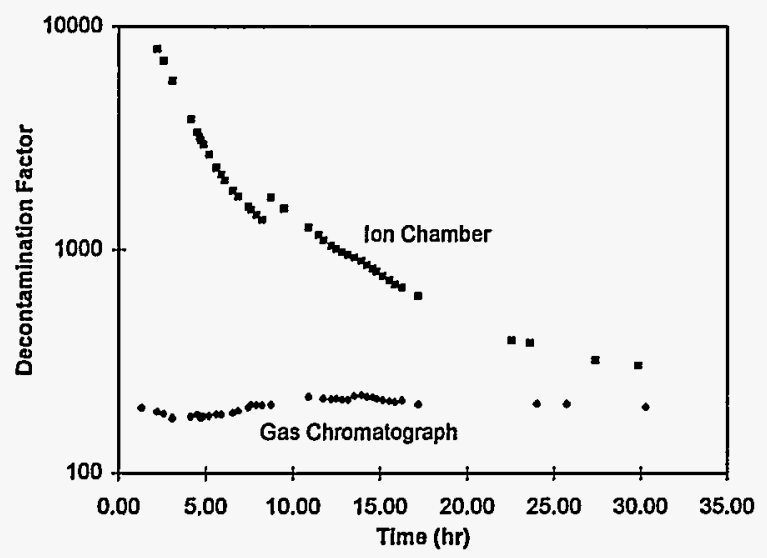

Figure 10. $1^{\text {st }}$ stage decontamination factor calculated by ion chamber and GC measurements.

\section{CONCLUSIONS}

Catalyst evaluation experiments indicated that $\mathrm{Pt} / \alpha-$ $\mathrm{Al}_{2} \mathrm{O}_{3}$ catalyst is superior to $\mathrm{Ni}$ catalysts. The $\mathrm{Pt}$ catalyst was stable in environments where coke formation occurred, while $\mathrm{Ni}$ catalysts were severely degraded by coke formation. Also, avoiding coke formation in a PMR by $\mathrm{O}_{2}$ injection was demonstrated.

A 2-stage system was tested with the non-tritium ITER mix in 61 days of continuous operation. No decrease in performance was observed over the duration of the test. Decontamination factor was found to increase with decreasing inlet rate. Overall decontamination factors in excess of $1.4 \times 10^{5}$ were obtained, but the exact value of the highest DF could not be determined because of analysis limitations.

Results of the 61-day test were used to design a 2stage PMR system for use in tritium testing. The PMR system was scaled up by a factor of 6 and built into a glovebox in TSTA. The ITER mix was injected into the PMR system for 31 hours, during which $4.5 \mathrm{~g}$ of tritium were processed. The $1^{\text {st }}$ stage had a DF $=200$ and the $2^{\text {nd }}$ stage had a $\mathrm{DF}=2.9 \times 10^{6}$. The overall $\mathrm{DF}=5.8 \times 10^{8}$, which is greater than ITER requirements.

\section{REFERENCE}

1. Willms, R.S., Wilhelm, R., and S. Konishi, "Performance Of A Palladium Membrane Reactor Using An Ni Catalyst For Fusion Fuel Impurities Processing," Fusion Engineering And Design, 28, 397-405 (1995).

2. Willms, R. S. and S. A. Birdsell, "Palladium Membrane Reactor Development At The Tritium Systems Test
Assembly," Fusion Technology, 28, No. 3, Part 1, 772777 (1995).

3. Birdsell, S. A. and R. S. Willms, "Modeling and Data Analysis of a Palladium Membrane Reactor for Tritiated Impurities Cleanup," Fusion Technology, 28, No. 3, Part 1, 530-537 (1995). 